\title{
Does co-infection with vector-borne pathogens play a role in clinical canine leishmaniosis?
}

Marta Baxarias ${ }^{1}$, Alejandra Álvarez-Fernández ${ }^{1}$, Pamela Martínez-Orellana', Sara Montserrat-Sangrà', Laura Ordeix ${ }^{1,2}$, Alicia Rojas ${ }^{3}$, Yaarit Nachum-Biala ${ }^{3}$, Gad Baneth ${ }^{3}$ and Laia Solano-Gallego ${ }^{1 *}$

\begin{abstract}
Background: The severity of canine leishmaniosis (CanL) due to Leishmania infantum might be affected by other vector-borne organisms that mimic its clinical signs and clinicopathological abnormalities. The aim of this study was to determine co-infections with other vector-borne pathogens based on serological and molecular techniques in dogs with clinical leishmaniosis living in Spain and to associate them with clinical signs and clinicopathological abnormalities as well as disease severity.

Methods: Sixty-one dogs with clinical leishmaniosis and 16 apparently healthy dogs were tested for Rickettsia conorii, Ehrlichia canis, Anaplasma phagocytophilum and Bartonella henselae antigens by the immunofluorescence antibody test (IFAT) and for E. canis, Anaplasma spp., Hepatozoon spp., Babesia spp. and filarioid DNA by polymerase chain reaction (PCR).

Results: Among the dogs examined by IFAT, the seroprevalences were: $69 \%$ for $R$. conorii, $57 \%$ for $E$. canis, $44 \%$ for A. phagocytophilum and 37\% for B. henselae; while the prevalences found by PCR were: $8 \%$ for Ehrlichia/Anaplasma, $3 \%$ for Anaplasma platys and 1\% for H. canis. No other pathogen DNA was detected. Statistical association was found between dogs with clinical leishmaniosis and seroreactivity to $R$. conorii antigen (Fisher's exact test: $P=0.025$, $\mathrm{OR}=4.1,95 \% \mathrm{Cl}=1-17$ ) and $A$. phagocytophilum antigen (Fisher's exact test: $P=0.002, \mathrm{OR}=14.3,95 \% \mathrm{Cl}=2-626$ ) and being positive to more than one serological or molecular tests (co-infections) (Mann-Whitney test: $U=243, Z=-2.6$, $\left.n_{1}=14, n_{2}=61, P=0.01\right)$ when compared with healthy dogs. Interestingly, a statistical association was found between the presence of R. conorii, E. canis, A. phagocytophilum and B. henselae antibodies in sick dogs and some clinicopathological abnormalities such as albumin and albumin/globulin ratio decrease and increase in serum globulins. Furthermore, seroreactivity with A. phagocytophilum antigens was statistically associated with CanL clinical stages III and IV.
\end{abstract}

Conclusions: This study demonstrates that dogs with clinical leishmaniosis from Catalonia (Spain) have a higher rate of co-infections with other vector-borne pathogens when compared with healthy controls. Furthermore, positivity to some vector-borne pathogens was associated with more marked clinicopathological abnormalities as well as disease severity with CanL.

Keywords: Canine leishmaniosis, Spain, Leishmania infantum, Rickettsia conorii, Ehrlichia canis, Anaplasma phagocytophilum, Anaplasma platys, Hepatozoon canis, Bartonella henselae, Co-infection

\footnotetext{
* Correspondence: laia.solano@uab.cat

${ }^{1}$ Departament de Medicina i Cirurgia Animals, Facultat de Veterinària,

Universitat Autònoma de Barcelona, Bellaterra, Spain

Full list of author information is available at the end of the article
} International License (http://creativecommons.org/licenses/by/4.0/), which permits unrestricted use, distribution, and reproduction in any medium, provided you give appropriate credit to the original author(s) and the source, provide a link to the Creative Commons license, and indicate if changes were made. The Creative Commons Public Domain Dedication waiver (http://creativecommons.org/publicdomain/zero/1.0/) applies to the data made available in this article, unless otherwise stated. 


\section{Background}

Canine leishmaniosis (CanL) is a zoonotic protozoan disease caused by Leishmania infantum endemic in the Mediterranean basin. Phlebotomus spp. sand flies are the only vector adapted for the biological transmission of $L$. infantum in Europe [1]. Dogs (Canis familiaris) are considered the main peridomestic reservoir of this parasite in endemic areas [2]. Prevalence of canine L. infantum infection can be as high as $67 \%$ in selected populations [3], but the prevalence of clinical disease is usually lower than $10 \%$ [4]. The most useful diagnostic methods of CanL include quantitative serological techniques and PCR, although the direct observation of amastigote forms of Leishmania spp. is also helpful in the clinical setting [4-6].

The clinical manifestations of CanL can vary from absence of clinical signs and clinicopathological abnormalities to a severe fatal clinical illness. The most common clinical signs are skin lesions, generalized lymphadenomegaly, progressive weight loss, decreased appetite, lethargy, muscular atrophy, exercise intolerance, splenomegaly, polyuria and polydipsia, ocular lesions, epistaxis, lameness, vomiting and diarrhea $[2,4,6]$.

In the Mediterranean basin, other canine vectorborne diseases are common. Some studies have documented Ehrlichia canis [7-12], Anaplasma platys $[10,12]$ and Rickettsia conorii $[8,9,13,14]$ infections in dogs. These intracellular Gram-negative bacteria are transmitted or likely transmitted by Rhipicephalus sanguineus (sensu lato) ticks [14-19]. It has been reported that the prevalence of these vector-borne infections is higher in communal shelter dogs and dogs that live outdoors $[9,12]$. The clinical characteristics of rickettsial disease in dogs can be similar to those caused by L. infantum. Anaplasma phagocytophilum $[8,9,11,12]$ is another canine pathogen transmitted by Ixodes ricinus ticks that can infect dogs and humans causing acute febrile illness or transient subclinical infection $[12,20]$. Other protozoan pathogens such as Babesia vogeli [10] and Hepatozoon canis [10] infect dogs in the Mediterranean basin and are also transmitted by $R$. sanguineus (s.l.) ticks $[15,17,18]$.

Bartonella spp. are vector-borne bacteria that cause diseases in humans and animals globally, including Europe [7, 8]. Numerous species of Bartonella have been identified as pathogenic to humans while Bartonella vinsonii berkhoffii and Bartonella henselae are associated with clinical disease in dogs [21]. Dirofilariasis due to Dirofilaria immitis or Dirofilaria repens is another vector-borne disease transmitted by mosquitoes from the family Culicidae present in Europe [8, 12, 22, 23] that can affect both animals and humans [24], causing cardiopulmonary or subcutaneous disease manifestations, respectively [24].
It has been reported that infections with other vectorborne organisms can affect the severity of CanL or mimic its clinical signs and/or clinicopathological abnormalities [25-27]. Some studies have described coinfection of $L$. infantum with other vector-borne diseases in dogs with typical signs of leishmaniosis [7, 10, 28, 29]. Other authors have demonstrated co-infections with $L$. infantum and E. canis, A. phagocytophilum and Bartonella spp. in the Mediterranean area [11, 26, 30, 31]. Mekuzas et al. [30] found that clinical signs were more frequent in dogs with dual L. infantum and E. canis infection than dogs with a single infection. Roura et al. [7] found that simultaneous infection with two or more pathogens should be expected in dogs living in areas which are highly endemic for several vector-borne pathogens, mainly in dogs kept predominantly outdoors and not regularly treated with ectoparacitides.

The aim of this study was to determine co-infections with other vector-borne pathogens in dogs with clinical leishmaniosis living in Catalonia (Spain) and to associate with clinical signs and clinicopathological abnormalities as well as with disease severity. These dogs were compared with healthy control dogs living in the same geographical area.

\section{Methods \\ Dogs}

The dogs included in this study were from Catalonia (Spain), an area endemic for CanL and other vectorborne diseases. Sixty-one sick dogs were diagnosed with clinical leishmaniosis based on compatible clinicopathological findings and a medium or high antibody level in a quantitative ELISA for the detection of L. infantumspecific antibodies and cytology or histology in some cases. Physical examination; a complete blood count (CBC) with blood smear examination (System Siemens Advia 120; Siemens Healthcare GmbH, Erlanger, Germany); a biochemical profile including creatinine, urea, total proteins, alanine transaminase (ALT) and total cholesterol (Analyzer Olympus AU 400; Beckman Coulter Inc., Brea, CA, USA); urinalysis with urinary protein creatinine ratio; and serum electrophoresis were performed. Reference intervals for the hematological and biochemical parameters were employed as previously described [32]. The dogs were examined at different veterinary centers: 33 were from Fundació Hospital Clínic Veterinari (Bellaterra, Barcelona, Spain), 15 were from Hospital Ars Veterinaria (Barcelona, Barcelona, Spain), 7 from Hospital Mediterrani Veterinaris (Reus, Tarragona, Spain) and 6 from Consultori Montsant (Falset, Tarragona, Spain). The following clinical signs were recorded: fever, weight loss, skin lesions, ocular lesions, lymphadenomegaly, muscular atrophy, splenomegaly, vomiting and diarrhea, joint pain, polyuria and polydipsia, lameness, 
epistaxis and neurological disorders. Lymphadenomegaly was classified as mild, moderate or marked depending on the relative size of the enlarged lymph node. Furthermore, the dogs were classified according to the LeishVet clinical staging system [4]. Leishmania real-time PCR (qPCR) was performed on blood from all dogs [33].

Sixteen apparently healthy dogs from Barcelona province, based on clinical history, normal physical examination, seronegative and qPCR-negative for Leishmania were also studied for comparison with the sick dogs. Healthy dogs were from Barcelona province and were also examined at the same veterinary centres.

\section{Samples}

Six millilitres of blood were collected from the dogs by jugular or metatarsal venipuncture for the laboratory tests described above. Blood was transferred into different tubes: ethylenediaminetetraacetic acid (EDTA) tubes for hematology and molecular testing, heparin for whole blood assay and plain serum tubes for biochemistry and serological testing. Once collected, samples were left at $4{ }^{\circ} \mathrm{C}$ overnight and then frozen at $-80{ }^{\circ} \mathrm{C}$ until further use.

All serum and whole blood extractions were performed at the time of diagnosis between 2014 and 2016 and stored at $-80{ }^{\circ} \mathrm{C}$ until use for this study.

\section{Quantitative ELISA for the detection of $L$. infantum- specific antibodies}

The in-house ELISA was performed on sera of all dogs studied as previously described [33]. All samples with an optical density (OD) equal or higher to three were studied using a two-fold serial dilution ELISA as described elsewhere [33].

\section{Whole blood assay and sandwich ELISAs for the detection} of canine IFN- $\gamma$

Whole blood assay and sandwich ELISAs for the detection of canine IFN- $\gamma$ were performed on blood of all dogs studied as previously described [34].

\section{IFAT for Rickettsia conorii, Ehrlichia canis, Anaplasma}

\section{phagocytophilum and Bartonella henselae antigens}

Indirect immunofluorescence assays for the detection of specific IgG antibody against $R$. conorii (MegaFLUO $^{\circ}$ RICKETTSIA conorii; Diagnostik Megacor, Hörbranz, Austria), E. canis (MegaFLUO ${ }^{\bullet}$ EHRLICHIA canis; Diagnostik Megacor. Hörbranz, Austria), A. phagocytophilum (MegaFLUO ${ }^{\circ}$ ANAPLASMA phagocytophilum; Diagnostik Megacor. Hörbranz, Austria) and B. henselae (MegaFLUO ${ }^{\circ}$ BARTONELLA henselae; Diagnostik Megacor. Hörbranz, Austria) antigens were performed on sera. IFATs were performed for 75 of the 77 dogs included in this study: 61 dogs with clinical leishmaniosis and 14 apparently healthy dogs. The samples were diluted to 1:64 with PBS and $20 \mu \mathrm{l}$ of every serum dilution was applied per well. The slides were incubated for $30 \mathrm{~min}$ at $37{ }^{\circ} \mathrm{C}$. After that, a washing procedure was performed. The slides were washed twice with PBS for 5 min and once with distilled water. After the washing procedure described, $15 \mu \mathrm{l}$ of FLUO FITC anti-dog IgG conjugate was added into each well. The slides were incubated for another $30 \mathrm{~min}$ at $37{ }^{\circ} \mathrm{C}$ in the dark to protect the photosensitive conjugate. The washing procedure described above was repeated. After the second washing procedure, some drops of mounting medium were added on the cover slips. The slides were evaluated using a fluorescence microscope (Leica DM6000 B; Leica Microsystems, Wetzlar, Germany) at 200× and 400× magnification and each well was compared to the fluorescence pattern seen in the positive and negative controls. All samples were examined by three different investigators to avoid errors of observation. All samples negative at 1:64 were considered negative and no further dilutions were done.

All samples with a positive result were further investigated using a two-fold serial dilution IFAT. The samples were diluted to $1: 128$ and 1:256.

If a high positive result was observed, the samples were diluted to $1: 512$ for $R$. conorii, and to both 1:512 and 1:1024 for E. canis, A. phagocytophilum and B. henselae antigens. At this point, if the samples had not reached a dilution with a negative result, the samples were classified as a high positive for $R$. conorii (>1:512) or as a high positive for E. canis, A. phagocytophilum or $B$. henselae antigens (>1:1024).

\section{Blood DNA extraction and PCR for the detection of Ehrlichia, Anaplasma spp., Hepatozoon and Babesia spp. and filaroid DNA}

Blood DNA extraction was performed as previously described [33, 35]. PCR was performed in samples from 76 of the 77 dogs included in the study: 60 with clinical leishmaniosis and 16 apparently healthy dogs.

\section{Ehrlichia and Anaplasma spp. DNA}

Samples were screened in duplicates for the presence of Ehrlichia/Anaplasma DNA using primers which amplify a $123 \mathrm{bp}$ of the $16 S \mathrm{rRNA}$ gene of the genera Anaplasma and Ehrlichia by a qPCR assay as previously described [36]. Positive samples from this reaction were further analysed in duplicates by conventional PCR using primers EHR16SD and EHR16SR which amplify a 345 bp fragment of the $16 S$ rRNA gene of species of the genera Anaplasma and Ehrlichia [37]. Positive and negative controls were included in both PCRs. 


\section{Hepatozoon and Babesia spp. DNA}

Detection of Babesia spp. and Hepatozoon spp. DNA was performed by a conventional PCR assay targeting a $400 \mathrm{bp}$ fragment of the $18 S$ rRNA gene by using the following primers ( 3 '-CCA GCA GCC GCG GTA ATT C-5') and ( $3^{\prime}$-CTT TCG CAG TAG TTY GTC TTT AAC AAA TCT-5') as described elsewhere [38]. All reactions were run in a StepOne Plus thermocycler (Applied Biosystems, Foster City, CA, USA). The samples were screened in duplicates, and positive and negative controls were included in each PCR run. Positive samples were tested by additional PCRs using primers specifically designed for the detection of a fragment of the $18 S \mathrm{rRNA}$ gene of Babesia spp. (PIROA/PIROB) [39].

\section{Filarioid DNA}

A high resolution melt (HRM) real-time PCR was performed as previously described [40] with some modifications. The qPCR was performed to amplify a partial sequence of the mitochondrial $12 S$ gene of filaroids of approximately 115 bp [41]. All reactions were run in duplicates in a StepOne Plus thermocycler (Applied Biosystems). Previously tested dog blood samples positive and negative for both canine filaroids were used as positive and negative controls, respectively.

\section{Sequencing PCR products}

Samples that were positive by PCR were sequenced as described elsewhere [42]. Only sequences with identity between $97 \%$ and $100 \%$ and coverage above $99 \%$ were considered as positive for an organism.

\section{Statistical analysis}

A descriptive study of the detection of antibodies, the number of co-infections detected in each dog, according to the results of the IFATs and PCRs performed, and the proportion of the antibody levels for each pathogen, was performed. The number of coinfections was calculated by the sum of the positive results for each test performed for each dog; therefore, the maximum number of co-infections was 7 (due to the fact that 4 IFATs and 3 PCRs were performed) and every $\operatorname{dog}$ had a result between 0 (no co-infections) and 7 (positive to all tests performed). Quantitative variables were assessed using the MannWhitney U-test and Spearman's correlation. The Mann-Whitney U-test was used to compare the medians of quantitative variables of healthy and sick dogs. Spearman's correlation was used to test for association between the number of co-infections detected and the clinical data of sick dogs that consisted of hematological and biochemical profile parameters, urinalysis with urinary protein creatinine ratio, and serum electrophoresis, the antibody levels in a quantitative ELISA for the detection of L. infantum-specific antibodies, the result for Leishmania qPCR and L. infantum IFN- $\gamma$ concentration. Qualitative variables of healthy and sick dogs were assessed using Chi-quare, Fisher's exact test, Kruskal-Wallis test and multivariable logistic regression. Fisher's exact test was also used to compare the detection of antibodies for the different pathogens with the clinical signs observed in each sick dog. Kruskal-Wallis test was used to compare the number of co-infections detected with sex, age and season at time of diagnosis, and the proportion of the level of antibodies detected for each pathogen with clinical data of sick dogs. Multivariable logistic regression was used to correlate the detection of antibodies with the clinical data of sick dogs; every factor was included in the analysis and those that were less significant $(P$-value $>0.2)$ were excluded until all factors presented a $P$-value $\leq 0.2$. The remaining factors were further studied using logistic regression. The Shapiro-Wilk test was performed to detect the normality of the distribution of the samples. A $P$-value $<0.05$ was considered statistically significant. The statistical analysis was performed using the $\mathrm{R}$ program i386 version 3.3.1 ( $\mathrm{R}$ Development Core Team) and the DeduceR program version 1.7-16 (Deducer: A data Analysis GUI for R) for Windows software.

\section{Results}

\section{Signalment and clinical data}

Both sexes were represented in the sick group with 37 males (61\%) and 24 females (39\%). Forty-two of 61 were intact, 30 males and 12 females. The median age at diagnosis was 5 years with a range from 5 months to 13 years. Forty-one dogs were purebred (67\%) and 20 were classified as mixed-bred (33\%).

The 61 dogs were classified in different stages of leishmaniosis after Solano-Gallego et al. [4]. Five (8\%) were classified as stage I with mild disease; $43(70 \%)$ were classified as stage II with moderate disease (31 classified as substage IIa and 12 classified in substage IIb); 10 $(16 \%)$ were classified as stage III with severe disease; and 3 (5\%) were classified as stage IV with very severe disease.

Both sexes were also represented in the healthy group with 5 males (31\%) and 6 females (38\%). Gender was not recorded in 5 dogs (31\%). The median age at diagnosis was 7 years with a range from 15 months to 13 years. Seven dogs (44\%) were purebred and 9 (56\%) were classified as mixed-bred.

No statistical differences in age, sex or breed were found between sick and apparently healthy dogs. 
IFAT

\section{Comparison of dogs with canine leishmaniosis and apparently healthy dogs}

The results of IFAT for $R$. conorii, E. canis, A. phagocytophilum and $B$. henselae antigens in sick and healthy dogs studied as well as PCR results are shown in Table 1. The most frequent seropositive serology was for $R$. conorii (52/75; 69\%), followed by E. canis (43/75; 57\%), A. phagocytophilum $(33 / 75 ; 44 \%)$ and B. henselae $(28 / 75 ; 37 \%)$ antigens. Of the total 75 assessed by IFAT, 11 (15\%) seroreacted with the 4 pathogen antigens, $16(21 \%)$ with 3 pathogens, 24 (32\%) with 2 of the pathogens screened and $16(21 \%)$ which seroreacted with 1 pathogen. Consequently, 67 (89\%) of the tested dogs seroreacted with at least 1 antigen by IFAT. Sera from $8(11 \%)$ of the tested dogs did not react in any IFAT test performed. The pattern of results of IFAT in dogs with clinical leishmaniosis and healthy dogs is summarized in Table 2.

Fifty seven of the 61 (93\%) dogs with clinical leishmaniosis had a positive result to at least one of the IFAT tests performed while 10 of the 14 (71\%) dogs in the healthy group also had a positive result. A significant difference was found when comparing the two groups of dogs (Fisher's exact test: $P=0.036, \mathrm{OR}=5.7,95 \% \mathrm{CI}=$ 1-35), thereby, dogs with clinical leishmaniosis were more likely to be positive to at least one of the IFAT compared to apparently healthy dogs. As shown in Table 1 , the most frequent seropositivity in dogs with clinical leishmaniosis was for $R$. conorii while $E$. canis antibodies were the most frequent in the healthy group.

Dogs with clinical leishmaniosis were more likely to have a positive result to more than one test (IFAT and PCR) (Mann-Whitney test:, $U=243, Z=-2.6, n_{1}=14, n_{2}$ $=61, P=0.01$ ) (Fig. 1), to be seroreactive to $R$. conorii
(Fisher's exact test: $P=0.025, \mathrm{OR}=4.1,95 \% \mathrm{CI}=1-17$ ) and to $A$. phagocytophilum (Fisher's exact test: $P=0.002$, $\mathrm{OR}=14.3,95 \% \mathrm{CI}=2-626$ ) antigens (Table 1) when compared with healthy dogs. No difference was found between seroreactivity to E. canis and B. henselae or being positive in the PCRs performed.

Of the 67 dogs that seroreacted to at least one pathogen, serial dilutions were performed, and the results are listed in Table 3. Healthy dogs were more likely to have a negative result or to have low antibody titers when compared with sick dogs (Table 3 ). Healthy dogs were likely to be negative for $R$. conorii (Fisher's exact test: $P$ $=0.025$, OR $=4.1,95 \% \mathrm{CI}=1-17)$ and $A$. phagocytophilum (Fisher's exact test: $P=0.002, \mathrm{OR}=14.3,95 \% \mathrm{CI}=$ 2-626) antigens while a higher number of healthy dogs were positive at the antibody titer of 1:64 for $E$. canis when compared with sick dogs (Fisher's exact test: $P=$ $0.014, \mathrm{OR}=0.2,95 \% \mathrm{CI}=0-0.9$ ).

Furthermore, a significant association was found in all dogs studied (healthy and sick dogs) between seroreactivity to $R$. conorii and seroreactivity to E. canis (Fisher's exact test: $P=0.044$, $\mathrm{OR}=2.9,95 \% \mathrm{CI}=1-9$ ) or $A$. phagocytophilum (Fisher's exact test: $P=0.012$, $\mathrm{OR}=4.2$, $95 \% \mathrm{CI}=1-16$ ), and seroreactivity to $A$. phagocytophilum and $E$. canis with high antibody titers (Chi-square test: $\left.\chi^{2}=26.36, d f=6, P<0.001\right)$.

\section{Comparison of dogs with canine leishmaniosis depending on co-infection status based on serological and molecular tests}

All statistically-significant associations found between the pathogens tested and laboratory abnormalities and clinical signs in sick dogs are summarized in Table 4.

Table 1 Results of IFAT for R. conorii, E. canis, A. phagocytophilum and B. henselae antigens and PCR for E. canis, Anaplasma spp., Hepatozoon spp., Babesia spp. and filarioids in dogs with clinical leishmaniosis and healthy dogs. A comparison of the groups was made with Fisher's exact test

\begin{tabular}{|c|c|c|c|c|}
\hline \multirow{2}{*}{$\begin{array}{l}\text { Assays } \\
\text { IFAT }\end{array}$} & \multicolumn{4}{|c|}{ Number $(\%, 95 \% \mathrm{Cl})$ of seroreactive dogs } \\
\hline & $\begin{array}{l}\text { Dogs with clinical leishmaniosis } \\
(n=61)\end{array}$ & $\begin{array}{l}\text { Healthy dogs } \\
(n=14)\end{array}$ & $\begin{array}{l}\text { Total dogs } \\
(n=75)\end{array}$ & P-value \\
\hline R. conorii & $46(75,65-86)$ & $6(43,17-69)$ & $52(69,59-80)$ & $0.025^{*}$ \\
\hline E. canis & $34(56,43-68)$ & $9(64,39-89)$ & $43(57,46-69)$ & 0.766 \\
\hline A. phagocytophilum & $32(53,40-65)$ & $1(7,0-21)$ & $33(44,33-55)$ & $0.002^{*}$ \\
\hline B. henselae & $25(40,28-52)$ & $3(21,0-43)$ & $28(37,26-48)$ & 0.147 \\
\hline PCR & $\begin{array}{l}\text { Dogs with clinical leishmaniosis } \\
(n=60)\end{array}$ & $\begin{array}{l}\text { Healthy dogs } \\
(n=16)\end{array}$ & $\begin{array}{l}\text { Total dogs } \\
(n=76)\end{array}$ & P-value \\
\hline Ehrlichia/Anaplasma spp. & $8(13,5-22)$ & $0(0)$ & $8(11,4-17)^{\mathrm{a}}$ & 0.191 \\
\hline H. canis and Babesia spp. & $1(2,0-5)$ & $0(0)$ & $1(1,0-4)^{b}$ & 0.606 \\
\hline Filarioid DNA & $0(0)$ & $0(0)$ & $0(0)$ & - \\
\hline
\end{tabular}

Abbreviations: $\mathrm{Cl}$ confidence interval, IFAT immunofluorescence antibody test, $P C R$ polymerase chain reaction

${ }^{a}$ Two dogs remained with a positive result for Anaplasma platys after performing a conventional PCR and sequencing

${ }^{b}$ One dog was detected with Hepatozoon canis infection. No Babesia spp. or filarioid DNA were detected

${ }^{*} P$-values statistically significant 
Table 2 Pattern of IFAT results in dogs with clinical leishmaniosis and healthy dogs for one or more antigens (R. conorii, E. canis, A. phagocytophilum and B. henselae)

\begin{tabular}{|c|c|c|c|c|}
\hline \multirow[t]{2}{*}{ Antigens } & \multicolumn{4}{|c|}{ Number $(\%, 95 \% \mathrm{Cl})$ of seroreactive dogs } \\
\hline & $\begin{array}{l}\text { Dogs with clinical leishmaniosis } \\
(n=57)\end{array}$ & $\begin{array}{l}\text { Healthy dogs } \\
(n=10)\end{array}$ & $\begin{array}{l}\text { Total dogs } \\
(n=67)\end{array}$ & $P$-value ${ }^{a}$ \\
\hline R. conorii alone & $6(11,3-19)$ & $0(0)$ & $6(9,2-16)$ & 0.58 \\
\hline E. canis alone & $5(9,1-16)$ & $2(20,0-45)$ & $7(10,3-18)$ & 0.279 \\
\hline A. phagocytophilum alone & $2(4,0-8)$ & $0(0)$ & $2(3,0-7)$ & 0.548 \\
\hline B. henselae alone & $1(2,0-5)$ & $0(0)$ & $1(1,0-4)$ & 0.673 \\
\hline R. conorii and E. canis & $6(11,3-19)$ & $4(40,10-70)$ & $10(15,6-24)$ & $0.035^{*}$ \\
\hline R. conorii and A. phagocytophilum & $3(5,0-11)$ & $0(0)$ & $3(4,0-9)$ & 0.458 \\
\hline R. conorii and B. henselae & $5(9,1-16)$ & $1(10,0-29)$ & $6(9,2-16)$ & 0.9 \\
\hline E. canis and A. phagocytophilum & $0(0)$ & $0(0)$ & $0(0)$ & - \\
\hline E. canis and B. henselae & 0 & $2(20,0-45)$ & $2(3,0-7)$ & $0.02^{*}$ \\
\hline A. phagocytophilum and B. henselae & $3(5,0-11)$ & $0(0)$ & $3(4,0-9)$ & 0.458 \\
\hline R. conorii, E. canis and A. phagocytophilum & $10(18,8-27)$ & $1(10,0-29)$ & $11(16,8-25)$ & 0.553 \\
\hline R. conorii, E. canis and B. henselae & $2(4,0-8)$ & $0(0)$ & $2(3,0-7)$ & 0.548 \\
\hline R. conorii, A. phagocytophilum and B. henselae & $3(5,0-11)$ & $0(0)$ & $3(4,0-9)$ & 0.458 \\
\hline E. canis, A. phagocytophilum and B. henselae & $0(0)$ & $0(0)$ & $0(0)$ & - \\
\hline R. conorii, E. canis, A. phagocytophilum and B. henselae & $11(19,9-30)$ & $0(0)$ & $11(16,8-25)$ & 0.195 \\
\hline
\end{tabular}

\section{Abbreviations: $\mathrm{Cl}$ confidence interval}

${ }^{\text {a }}$ "Pisher's exact test was performed

${ }^{*} P$-values statistically significant

When dogs with clinical leishmaniosis were compared with the same sick group depending on each pathogen specific seroreactivity (sick dogs seroreactive to one antigen vs sick dogs seronegative to the same pathogen), no statistical association was found between sex or the blood parasite load of L. infantum and any of the pathogens tested by IFAT. The presence of $R$. conorii antibodies was more frequent among sick dogs that were older than 5 years-old at time of diagnosis (Logistic regression: $\chi^{2}=8.47, d f=1, P=0.0036$, OR $\left.=1.03\right)$, sick dogs with a lower albumin/globulin ratio than the average of the sick group (Logistic regression: $\chi^{2}=5.27, d f=$ $1, P=0.0217$, OR $=0.2$ ) (Fig. 2), sick dogs with a lower concentration of lymphocytes than the average of the

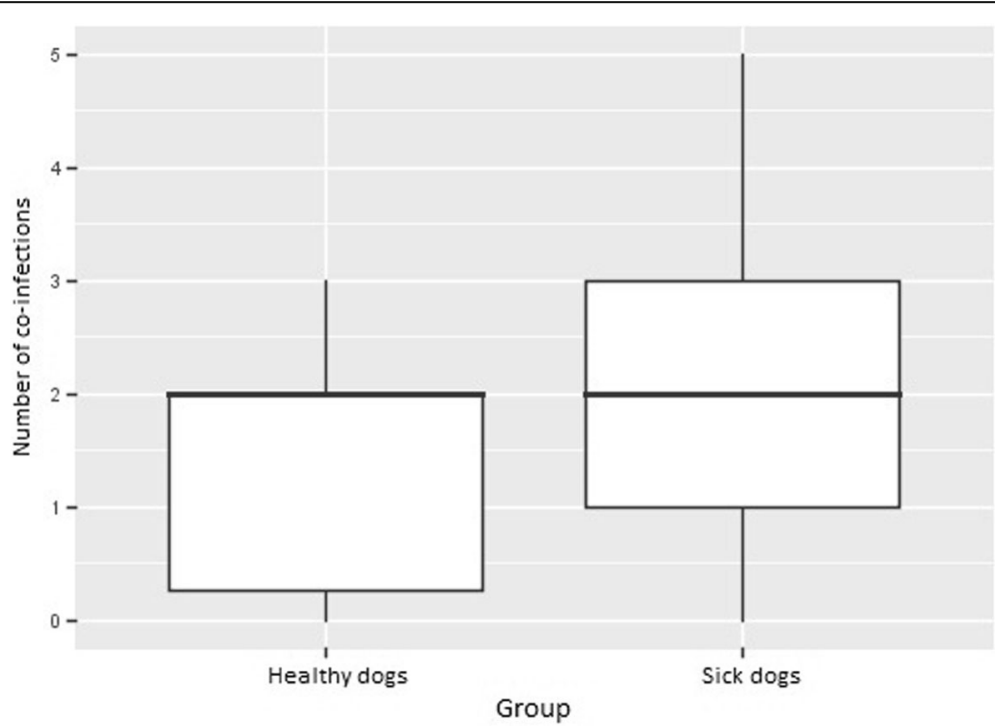

Fig. 1 Comparison of the number of co-infections detected by IFAT and PCR between dogs with clinical leishmaniosis and apparently healthy dogs. A comparison of the means was performed with Mann-Whitney U-test (Mann-Whitney test: $U=243, Z=-2.6 n_{1}=14, n_{2}=61, P=0.01$ ) 
Table 3 IFAT antibody titers for R. conorii, E. canis, A. phagocytophilum and B. henselae antigens in dogs with clinical leishmaniosis and healthy dogs. Fisher's exact test was performed

\begin{tabular}{|c|c|c|c|}
\hline \multirow{2}{*}{$\begin{array}{l}\text { Antibody } \\
\text { titers }\end{array}$} & \multirow[t]{2}{*}{ Antigens } & \multicolumn{2}{|c|}{ Number $(\%, 95 \% \mathrm{Cl})$ of seroreactive dogs } \\
\hline & & $\begin{array}{l}\text { Dogs with clinical } \\
\text { leishmaniosis } \\
(n=61)\end{array}$ & $\begin{array}{l}\text { Healthy dogs } \\
(n=14)\end{array}$ \\
\hline \multirow[t]{4}{*}{$<64$} & R. conorii* & $15(25,14-35)$ & $8(57,31-83)$ \\
\hline & E. canis & $27(44,32-57)$ & $5(36,11-61)$ \\
\hline & A. phagocytophilum** & $29(48,35-60)$ & $13(93,79-100)$ \\
\hline & B. henselae & $36(59,47-71)$ & $11(79,57-100)$ \\
\hline \multirow[t]{4}{*}{64} & R. conorii & $12(20,10-30)$ & $2(14,0-33)$ \\
\hline & E. canis ${ }^{* * *}$ & $17(28,17-39)$ & $9(64,39-89)$ \\
\hline & A. phagocytophilum & $17(28,17-39)$ & $1(7,0-21)$ \\
\hline & B. henselae & $6(10,2-17)$ & $1(7,0-21)$ \\
\hline \multirow[t]{4}{*}{128} & R. conorii & $0(0)$ & $0(0)$ \\
\hline & E. canis & $3(5,0-10)$ & $0(0)$ \\
\hline & A. phagocytophilum & $4(7,0-13)$ & $0(0)$ \\
\hline & B. henselae & $8(13,5-22)$ & $1(7,0-21)$ \\
\hline \multirow[t]{4}{*}{256} & R. conorii & $10(16,7-26)$ & $0(0)$ \\
\hline & E. canis & $3(5,0-10)$ & $0(0)$ \\
\hline & A. phagocytophilum & $3(5,0-10)$ & $0(0)$ \\
\hline & B. henselae & $10(16,7-26)$ & $1(7,0-21)$ \\
\hline \multirow[t]{4}{*}{512} & R. conorii & $15(26,15-37)$ & $4(29,5-52)$ \\
\hline & E. canis & $2(3,0-8)$ & $0(0)$ \\
\hline & A. phagocytophilum & $4(7,0-13)$ & $0(0)$ \\
\hline & B. henselae & $0(0)$ & $0(0)$ \\
\hline$>512$ & R. conorii & $9(15,6-24)$ & $0(0)$ \\
\hline \multirow[t]{3}{*}{1024} & E. canis & $8(13,5-22)$ & $0(0)$ \\
\hline & A. phagocytophilum & $3(5,0-10)$ & $0(0)$ \\
\hline & B. henselae & $1(2,0-5)$ & $0(0)$ \\
\hline \multirow[t]{3}{*}{$>1024$} & E. canis & $1(2,0-5)$ & $0(0)$ \\
\hline & A. phagocytophilum & $1(2,0-5)$ & $0(0)$ \\
\hline & B. henselae & $0(0)$ & $0(0)$ \\
\hline
\end{tabular}

Abbreviation: $\mathrm{Cl}$ confidence interval

${ }^{*} P=0.025,{ }^{*} P=0.002,{ }^{* * *} P=0.014$

group (Logistic regression: $\chi^{2}=4.66, d f=1, P=0.0309$, $\mathrm{OR}=0.9$ ) and a high positive antibody level by the $L$. infantum quantitative ELISA (Chi-square test: $\chi^{2}=13.04$, $d f=3, P=0.005)$. The presence of $E$. canis antibodies was only associated with sick neutered dogs (Chi-square test: $\left.\chi^{2}=6.84, d f=1, P=0.033\right)$ while the presence of $A$. phagocytophilum antibodies was more frequent in sick dogs with an increase of total protein (Logistic regression: $X^{2}=4.64, d f=1, P=0.0312$, OR $\left.=1.3\right)$, beta globulins (Logistic regression: $\chi^{2}=4.28, d f=1, P=0.0385$; OR =3.6) and gamma globulins (Logistic regression: $\chi^{2}=$ 5.37, $d f=1, P=0.0204, \mathrm{OR}=1.5)$ compared to the average of the tested sick group, a decrease of albumin (Logistic regression: $\chi^{2}=9.82, d f=1, P=0.0017, \mathrm{OR}=0.2$ ), lower albumin/globulin ratio (Logistic regression: $\chi^{2}=$ 12.77, $d f=1, P=0.0003, \mathrm{OR}=0$ ) (Fig. 2) compared to the average of sick group, a high positive antibody level by the L. infantum quantitative ELISA (Chi-square: $\chi^{2}=$ $13.04, d f=3, P=0.003$ ) and dogs classified in stage III or IV of the LeishVet clinical staging for L. infantum (Chisquare: $\chi^{2}=9.38, d f=4, P=0.042$ ) (Fig. 3 ) and being diagnosed in spring or winter (Chi square: $\chi^{2}=10.59, d f=$ $3, P=0.014)$. The presence of $B$. henselae antibodies in sick dogs was associated with an increase of total protein (Logistic regression: $\chi^{2}=11.67, d f=1, P=0.0006, \mathrm{OR}=$ 1.8), beta globulins (Logistic regression: $\chi^{2}=10.44, d f=$ $1, P=0.0012, \mathrm{OR}=2.3$ ) and gamma globulins (Logistic regression: $X^{2}=6.75, d f=1, P=0.0094$, $\mathrm{OR}=1.5$ ), a low 
Table 4 Summary of signalment, clinical signs, laboratory abnormalities, and the results of diagnostic tests for leishmaniosis significantly associated with seroreactivity to different antigens tested by IFAT and with positive results tested by PCR in dogs with clinical leishmaniosis

\begin{tabular}{|c|c|c|c|}
\hline $\begin{array}{l}\text { Test } \\
\text { performed }\end{array}$ & Pathogen & Laboratory abnormalities ${ }^{\mathrm{a}, \mathrm{b}}$ & Clinical signs $^{c}$ \\
\hline \multirow[t]{4}{*}{ IFAT } & R. conoriil & $\begin{array}{l}\text { Increase: ns } \\
\text { Decrease: albumin, albumin/globulin ratio, lymphocyte } \\
\text { concentration }\end{array}$ & ns \\
\hline & E. canis ${ }^{\mathrm{e}}$ & $\begin{array}{l}\text { Increase: total protein, gamma globulins } \\
\text { Decrease: albumin, albumin/globulin ratio, hematocrit, } \\
\text { hemoglobin, RBC }\end{array}$ & ns \\
\hline & A. phagocytophilum ${ }^{f}$ & $\begin{array}{l}\text { Increase: total protein, beta globulins, gamma globulins } \\
\text { Decrease: albumin, albumin/globulin ratio }\end{array}$ & No presence of lameness \\
\hline & B. henselae & $\begin{array}{l}\text { Increase: total protein, beta globulins, gamma globulins } \\
\text { Decrease: albumin/globulin ratio, hematocrit, hemoglobin }\end{array}$ & Marked lymphadenomegaly \\
\hline \multirow[t]{2}{*}{$P C R$} & Ehrlichia/Anaplasma & $\begin{array}{l}\text { Increase: ns } \\
\text { Decrease: hematocrit, RBC, platelet concentration }\end{array}$ & ns \\
\hline & Hepatozoon/Babesia & $\begin{array}{l}\text { Increase: ns } \\
\text { Decrease: ns }\end{array}$ & ns \\
\hline Co-infections $^{9}$ & & $\begin{array}{l}\text { Increase: total protein, beta globulins, gamma globulins, UPC } \\
\text { Decrease: albumin, albumin/globulin ratio, lymphocyte } \\
\text { concentration, hematocrit, hemoglobin, MCH }\end{array}$ & ns \\
\hline
\end{tabular}

Abbreviations: $n s$ non-significant, UPC urinary protein/creatinine ratio, MCH mean corpuscular hemoglobin

${ }^{a}$ All statistically significant associations are present in the result section of this manuscript

${ }^{b}$ No statistically significant association was found between the tested pathogens and other laboratorial abnormalities recorded (creatinine, urea, ALT, total cholesterol, urinary protein/creatinine ratio, leucocyte, monocyte, neutrophil, eosinophil and reticulocyte concentrations)

${ }^{c}$ No statistically significant association was found between the tested pathogens and the other clinical signs recorded (fever, weight loss, skin lesions, ocular lesions, muscular atrophy, splenomegaly, vomiting and diarrhea, joint pain, polyuria and polydipsia, epistaxis and neurological disorders)

${ }^{d}$ Statistically significant association was also found with older age ( $>5$ year-old) and a high positive antibody level by L. infantum quantitative ELISA

eStatistically significant association was also found with neutering

fStatistically significant association was also found with a high positive antibody level by L. infantum quantitative ELISA, being in stage III or IV of LeishVet clinical staging for $L$. infantum and being diagnosed in spring or winter

${ }^{9}$ Statistically significant association was also found with high parasite load of $L$. infantum and older age

albumin/globulin ratio (Logistic regression: $X^{2}=7.98, d f$ $=1, P=0.0047$, OR $=0.1$ ), hematocrit (Logistic regression: $\left.\quad \chi^{2}=7.1, \quad d f=1, \quad P=0.0077, \quad \mathrm{OR}=0.9\right) \quad$ and hemoglobin (Logistic regression: $\chi^{2}=6.72, d f=1, P=$ 0.0095 , OR $=0.8$ ).

When dogs with clinical leishmaniosis were compared with dogs from the same group that had different antibody titers $(<1: 64,1: 64,1: 128,1: 256,1: 512 ; 1: 1024$ and $>1: 1024$ for E. canis, A. phagocytophilum and B. henselae and <1:64, 1:64, 1:128, 1:256, 1:512 and >1:512 for R. conorii), no significant association was found between sex, age, clinical signs and the clinical stage of leishmaniosis. A comparison between the average of different antibody titers was performed. The sick dogs that had a high positive (>1:512) antibody titer for $R$. conorii antigen were positively associated with a decrease in albumin (Kruskal-Wallis H-test: $X^{2}=12.98, \quad d f=4, \quad P=$ $0.0113)$, while a decrease of the albumin/globulin ratio was associated with an increase of antibody titers for $R$. conorii antigen (Kruskal-Wallis H-test: $\chi^{2}=12.5, d f=4$, $P=0.014)$. Furthermore, sick dogs that had antibody titers for $R$. conorii antigen at 1:256 and 1:512 dilutions were associated with production of IFN- $\gamma$ after blood stimulation with $L$. infantum antigen (Chi-square test: $\left.X^{2}=10.74, \quad d f=4, \quad P=0.028\right)$. These dogs with leishmaniosis were also associated with being diagnosed in the autumn (Chi-square test: $\chi^{2}=11.44, d f=3, P=$ 0.011). No other pathogens were associated with the production of IFN- $\gamma$ after blood stimulation with $L$. infantum antigen.

A significant association was found between a high $E$. canis antibody titer $(>1: 512)$ and a decrease in albumin (Logistic regression: $\chi^{2}=6.88, d f=1, P=0.0087, \mathrm{OR}=$ 0.2 ), albumin/globulin ratio (Logistic regression: $\chi^{2}=$ 7.24, $d f=1, P=0.0071, \mathrm{OR}=0$ ), hematocrit (Logistic regression: $\quad \chi^{2}=7.97, \quad d f=1, \quad P=0.0048, \quad$ OR $\left.=0.7\right)$, hemoglobin (Logistic regression: $\chi^{2}=7.76, d f=1, P=$ 0.0053, OR $=0.6$ ), RBC (Logistic regression: $\chi^{2}=6.14, d f$ $=1, P=0.0132$, OR $=0.1$ ) and an increase in gamma globulins (Logistic regression: $\chi^{2}=8.06, d f=1, \quad P=$ 0.0045 , $\mathrm{OR}=2.4$ ) and total protein (Logistic regression: $X^{2}=9.81, d f=1, P=0.0017, \mathrm{OR}=3$ ). Furthermore, a significant association was found between high $A$. phagocytophilum antibody titers $(>1: 512)$ and a decrease in albumin (Kruskal-Wallis H-test: $\chi^{2}=21.68, d f=6, P=$ 0.0014 ) and the albumin/globulin ratio (Kruskal-Wallis H-test: $\left.\chi^{2}=21.65, d f=6, P=0.0014\right)$.

When dogs with clinical leishmaniosis were compared with the same sick group according to the antibody titers, no statistical association was found between high $B$. 

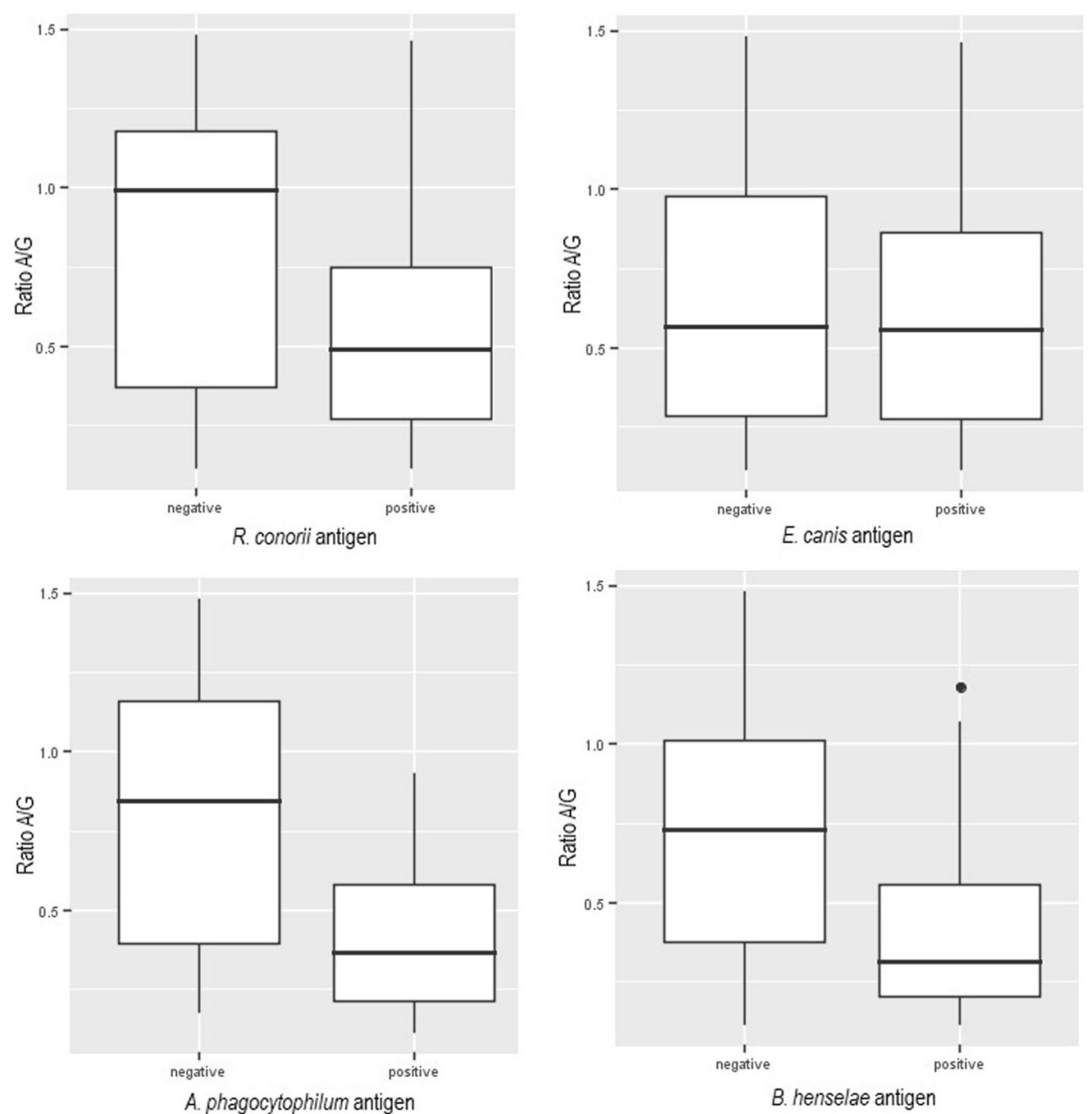

Fig. 2 The relationship of the albumin/globulin ratio with the results (positive or negative) of the different IFAT performed at a dilution of 1:64. A comparison of the means was performed with logistic regression with the following results: $R$. conorii $\left(x^{2}=5.27, P=0.0217, O R=0.2\right), E$. canis $\left(x^{2}=\right.$ $0.07, P=0.7864, \mathrm{OR}=0.8)$, A. phagocytophilum $\left(X^{2}=12.77, P=0.0003, \mathrm{OR}=0\right)$ and $B$. henselae $\left(X^{2}=7.98, P=0.0047, \mathrm{OR}=0.1\right)$ antigens

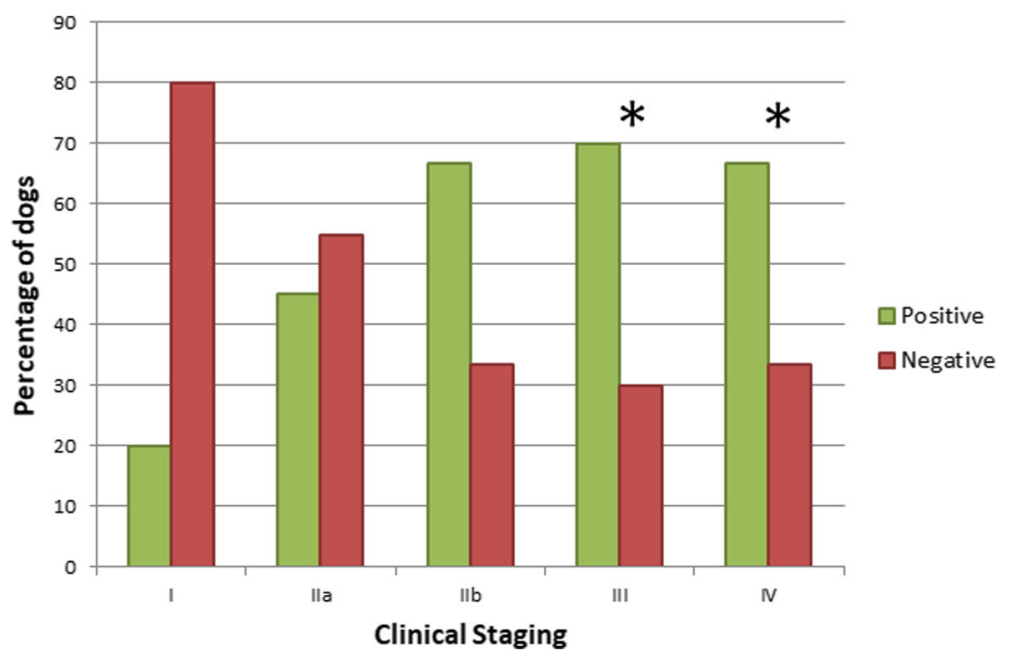

Fig. 3 Results of IFAT for A. phagocytophilum antigen in dogs with clinical leishmaniosis based on the LeishVet clinical staging. Fisher's exact tests were performed; asterisks indicate $P=0.042$ 
henselae antibody titers and clinicopathological abnormalities.

When dogs with clinical leishmaniosis were compared with dogs from the same group that did not show the same clinical signs, no statistically-significant association was found between clinical signs and a positive result for $R$. conorii and E. canis tested by IFAT. Lymphadenomegaly was the only clinical sign significantly associated with $B$. henselae tested by IFAT (Fisher's exact test: $P=$ 0.044, $\mathrm{OR}=4,95 \% \mathrm{CI}=1-19)$. In addition, B. henselae seroreactivity was associated with marked lymphadenomegaly in sick dogs (Logistic regression: $\chi^{2}=8.1, d f=1$, $P=0.0044$, OR $=2.3$ ). Interestingly, $A$. phagocytophilum seroreactivity was associated with a lower probability of suffering from lameness (Fisher's exact test: $P=0.021$, $\mathrm{OR}=0,95 \% \mathrm{CI}=0-0.9$ ) when compared with sick dogs that did not seroreact with A. phagocytophilum antigen.

When dogs with clinical leishmaniosis were compared with dogs from the same group divided according to the number of co-infections (as detected by both IFAT and PCR), no significant association was found between sex or the clinical stage of leishmaniosis. A significant association between the number of co-infections and the blood parasite load of $L$. infantum $\left(r_{(66)}=0.3, P=\right.$ $0.0252)$, age at time of diagnosis $\left(r_{(67)}=0.2, P=0.0496\right)$, total protein $\left(r_{(68)}=0.4, P=0.0005\right)$, urinary protein $/$ creatinine ratio (UPC) $\left(r_{(42)}=0.3, P=0.0256\right)$, albumin $\left(r_{(66)}=-0.4, \quad P=0.0008\right)$, albumin/globulin ratio $\left(r_{(62)}\right.$ $=-0.5, P=0.0001)$, beta globulins $\left(r_{(56)}=0.4, P=0.0025\right)$, gamma globulins $\left(r_{(56)}=0.4, P=0.002\right)$, hematocrit $\left(r_{(56)}\right.$ $=-0.3, P=0.0446)$, hemoglobin $\left(r_{(57)}=-0.3, P=0.045\right)$, mean corpuscular haemoglobin $(\mathrm{MCH})\left(r_{(48)}=-0.4, P=\right.$ $0.0074)$ and lymphocyte concentration $\left(r_{(54)}=-0.3, P=\right.$ 0.0493) was found by Spearman's correlation in sick dogs.

\section{PCR}

\section{Detection of Ehrlichia and Anaplasma spp. DNA}

Of the 60 dogs with clinical leishmaniosis assessed, 8 (10.5\%) were positive for Ehrlichia and Anaplasma by real-time PCR. However, positive amplicons for E. canis and Anaplasma qPCR did not produce a conclusive sequence. Of those 8 dogs, only $2(2 / 8 ; 25 \%)$ maintained a positive result after performing a conventional PCR. Sequencing showed that both dogs were detected with $A$. platys (Table 5 ). All apparently clinically healthy dogs resulted negative.

When comparing the results of the PCR between dogs with clinical leishmaniosis and healthy dogs with Fisher's exact test, no difference was found between the groups.

When dogs with clinical leishmaniosis that were PCR positive were compared to PCR negative sick dogs, a statistically significant association was found between a PCR positive result and a decreased hematocrit (Logistic regression: $\left.\chi^{2}=4.8, d f=1, P=0.0281, \quad \mathrm{OR}=0.9\right), \quad \mathrm{RBC}$ (Logistic regression: $\chi^{2}=3.9, d f=1, P=0.048, \mathrm{OR}=0.4$ ) and platelet concentration (Logistic regression: $\chi^{2}=3.98$, $d f=1, P=0.0461$, OR $=0.9)$.

No significant association was found between the origin of the dogs (Barcelona or Tarragona) and a positive result by PCR, although the two dogs that had a positive result in the conventional PCR were from Tarragona.

\section{Detection of Hepatozoon spp., Babesia spp. and filarioid DNA}

Of the 77 dogs assessed, only 1 (1.3\%) had a positive result by PCR for Hepatozoon spp. This dog was diagnosed with clinical leishmaniosis. After sequencing, the pathogen found was $H$. canis (Table 5). Babesia and filarioid DNA were not detected in any of samples studied.

No statistically significant association was found between the positive $H$. canis PCR result and any of the clinical characteristics of the sick dogs assessed.

\section{Discussion}

Previous studies have suggested that CanL could be affected by other vector-borne pathogens. De Tommasi et al. [26] found that infection with two or more vectorborne pathogens could complicate the clinical presentation and severity of hematological abnormalities in dogs with vector-borne disease. Mekuzas et al. [30] examined naturally exposed dogs with L. infantum and E. canis coinfection and proposed that the increase in clinical signs in co-infection is associated with a synergistic pathological effect between both pathogens. Furthermore, it was suggested that $E$. canis infection could contribute to the establishment of CanL [30]. In addition, Baneth et al. [27] examined three dogs with $E$. canis and $H$. canis coinfection in the same host cell and suggested that infection with one pathogen could permit or enhance invasion of another. Conversely, Tabar et al. [43] examined dogs with leishmaniosis and filariosis to detect filarial spp., Wolbachia spp. and Leishmania co-infection, and although an increase of disease severity and clinical signs was observed with Leishmania-filarial co-infection, it was also suggested that Wolbachia could have a protective role against Leishmania infection.

The present study demonstrated the presence of coinfections with vector-borne pathogens in dogs with clinical leishmaniosis living in the Mediterranean basin. To the best of our knowledge, a statistically significant relationship between sick dogs and a higher proportion of co-infections with the detection of $R$. conorii or $A$. phagocytophilum antibodies, when compared with healthy dogs, was found for the first time. In agreement with these results, a recent study documented that co-infection with several tick-borne pathogens caused clinical progressions of leishmaniosis in foxhounds in 


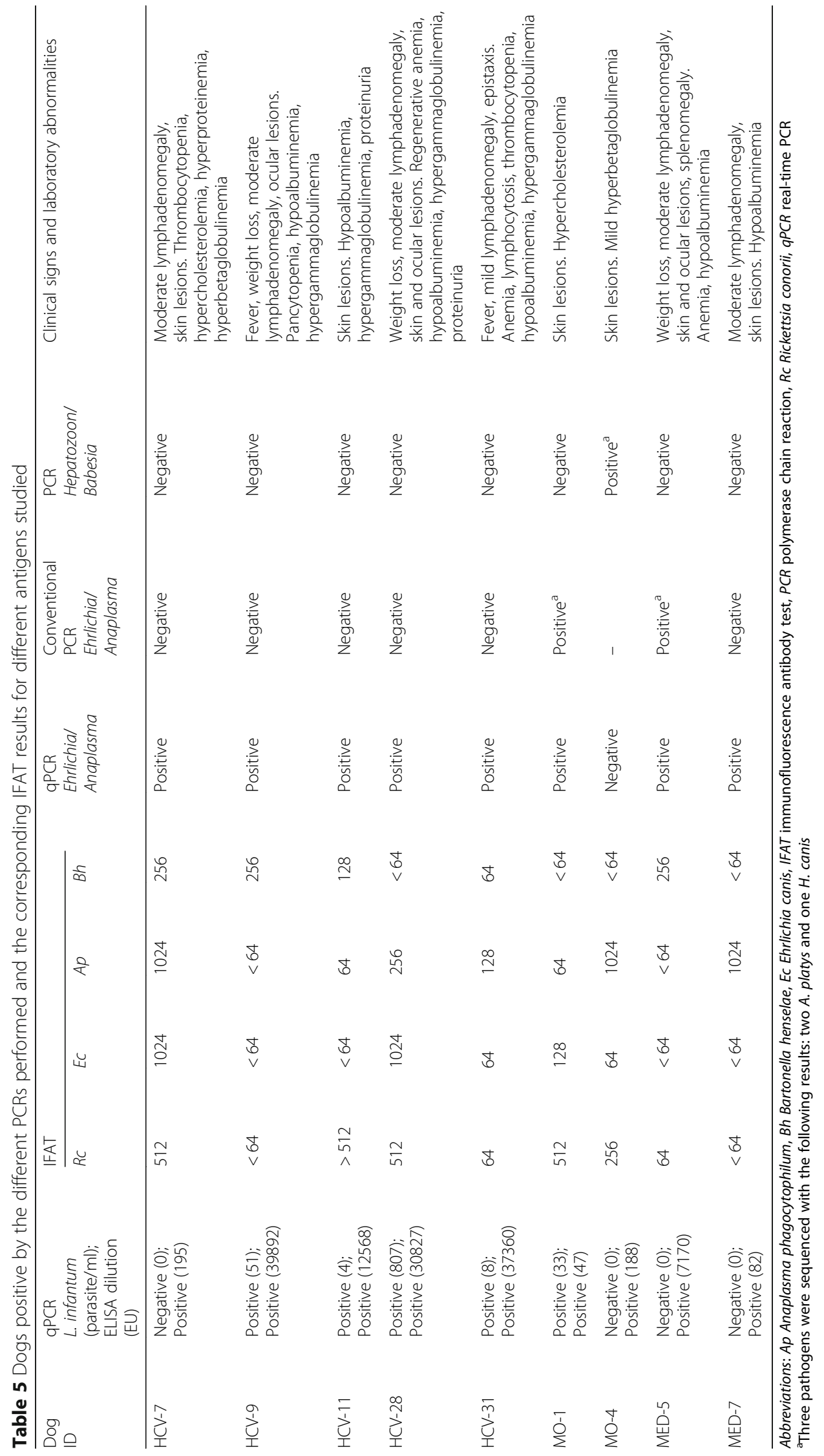


the USA [44]. In disagreement with previous reports $[26,30,45-47]$, no association was found between seroreactivity to $E$. canis antigen and sick dogs with leishmaniosis. Interestingly, a positive trend was noted in our study in the association between seroreactivity to $B$. henselae antigen and sick dogs when compared with healthy dogs, although this was not statistically significant. A previous study found a significant percentage of seroreactivity to Bartonella antigens in sick dogs with clinical signs compatible with vector-borne diseases when compared to clinically healthy dogs in the USA where a large number of dogs were evaluated [48].

This study showed that more marked clinicopathological abnormalities such as decrease in albumin or RBC numbers or increase in globulins were noted in dogs with clinical leishmaniosis with a higher number of coinfections compared to dogs with CanL and a lower number of co-infections. This is in agreement with previous studies [49-51]. Those studies demonstrated more marked thrombocytopenia, an evident reduction of platelet aggregation response, a significant increase in activated partial thromboplastin time (APTT) and a reduction of the albumin/globulin ratio in dogs with clinical leishmaniosis co-infected with E. canis [49-51]. Here, in the present study, we report for the first time that certain clinicopathological abnormalities are more marked in dogs with co-infections based on positive serology for R. conorii, A. phagocytophilum, E. canis and B. henselae. It is important to highlight that based on the present findings, moderate to marked hypoalbuminemia or hyperglobulinemia in dogs with clinical leishmaniosis should arouse the suspicion of co-infections with other vector-borne pathogens. It has been shown that infection with tick-borne pathogens such as $R$. conorii, $B$. henselae, A. platys, A. phagocytophilum and E. canis may induce a decrease in serum concentration of negative acute phase proteins and an increase of positive acute phase proteins $[19,52-55]$. Albumin is a negative acute phase protein whose level tends to decrease in inflammation or infection $[56,57]$.

Furthermore, it is noteworthy to mention that pathogen DNA was only detected in dogs with clinical leishmaniosis although no significant difference in detection was found when comparing with healthy dogs. Anaplasma platys and $H$. canis were confirmed as infecting dogs with clinical leishmaniosis by PCR. Interestingly, a significant association was found between dogs positive for E. canis and Anaplasma spp. by PCR and a low hematocrit, $\mathrm{RBC}$ and platelet concentration, which are typical clinicopathological findings in canine ehrlichiosis or anaplasmosis that could be worsened due to the coinfection [16, 54, 58, 59].

In this study, clinical signs common in leishmaniosis such as skin lesions, progressive weight loss, generalized lymphadenomegaly or splenomegaly were also evaluated. Lymphadenomegaly was the only clinical sign statistically associated with being seroreactive to $B$. henselae antigen. Furthermore, seroreactivity to $B$. henselae antigen was also positively associated with the degree of severity of lymphadenomegaly classified as mild, moderate or marked. Lymphadenomegaly is common in both diseases, leishmaniosis and bartonellosis [2, 4, 21]. Interestingly, an association was found between antibodies against A. phagocytophilum and more advanced clinical stages of leishmaniosis (LeishVet stage III and IV) in agreement with a recent study [44]. Further studies are needed to understand the relationship between coinfections and clinical leishmaniosis in dogs.

Previous studies have evaluated the serological and molecular evidence of exposure to vector-borne pathogens in dogs in Catalonia (Spain) [7, 8, 10, 12]. When comparing our results to those of these studies, we found a high increase of seropositivity rates to other pathogens when studying dogs with clinical leishmaniosis. For example, the seroprevalence found for $E$ canis in our study was $56 \%$ in dogs with clinical leishmaniosis, while those other studies found seroprevalences of $16.7 \%$ [8] and 5\% [12] for E. canis in healthy dogs. Interestingly, the seroprevalence found for Bartonella spp. was rather similar to that found in other studies carried out in Catalonia and the Island of Mallorca. Roura et al. [7] found a seroprevalence of $28 \%$ for B. vinsonii berkhoffii while another study found a seroprevalence of $16.8 \%$ for B. henselae and $1.1 \%$ for B. vinsonii berkhoffii [8].

Combining the serological and molecular results of the present study with the findings from previous literature, it is noteworthy to remark that co-infections patterns are different in several geographical regions where the dogs with leishmaniosis live and there is variability in their life style, exposure to ticks and fleas, the species of ectoparasites present in the area, and also on the preventative measures applied against ticks and fleas. For example, in the present study, $A$. platys and $H$. canis were only confirmed by PCR in dogs from the Tarragona area. In the Mediterranean basin, where mosquitoes and R. sanguineus (s.l.) ticks are common, it would be expected that the pathogens related to this tick species would be also prevalent $[15,24,60]$. However, comparing the present study with other recent studies from Croatia [61], Greece [62, 63], Corsica [64], Cyprus [65], Tunisia [66] and Israel [67], it is evident that E. canis, Hepatozoon spp. Babesia spp. and Dirofilaria spp. are circulating abundantly in those countries while, the results suggest that they are less common in Catalonia.

PCR is a technique that detects pathogen DNA and can, therefore, confirm infection although a negative result does not completely exclude it. Serological techniques, such as ELISA and IFAT, on the other hand, 
detect antibodies formed due to current infection or past exposure to the pathogen studied. Quantitative serology may be used to detect seroconversion, but seropositivity may also result from cross-reaction with antibodies formed against other organisms with similar antigens. PCR also allows identification of the pathogen. Due to the aforementioned characteristics, it is recommended to use both techniques for diagnosis of some infectious diseases $[10,68,69]$. In the present study, the results for the different PCR performed had some important limitations in the detection of positive samples, possibly due to the low pathogen load in the blood. It is important to note that with the particular pathogens studied, serial evaluations of blood parasitaemia or bacteraemia by PCR are recommended to enhance the likelihood of PCR detection [70]. In the present study, no repeated testing of the same dogs was performed and serology was not used to detect seroconversion, although seroconversion could have been helpful in the detection of a higher number of acute infections $[19,70]$. Furthermore, in the present study, no PCR was performed to detect Rickettsia spp. such as $R$. conorii due to the low rickettsiaemia usually found in dogs $[10,19,71]$. PCR to detect Bartonella was also not performed. These bacteria are often cultured with an enrichment medium for insect cell culture growth (BAPGM) prior to PCR testing to increase the likelihood of detecting this species [72].

The different cross-reactions that could have occurred in this study should also be considered. It has been reported that positive reaction found in serological tests for $R$. conorii in dogs might be due to infection with other spotted fever group (SFG) Rickettsia spp. such as $R$. massiliae, R. slovaca or $R$. aeschlimannii, which are common in ticks in the Mediterranean basin countries $[19,73,74]$. Furthermore, serological cross-reactivity between $A$. phagocytophilum and A. platys is common, due to their antigenic similarity $[12,75,76]$. In Europe, $A$. phagocytophilum is usually transmitted by $I$. ricinus ticks while $A$. platys is suspected to be transmitted by $R$. sanguineus (s.l.) [15-17]. Taking into account that the main tick that inhabits the Barcelona area is $R$. sanguineus (s.l.) [77], it can be suggested that the positive serological reactivity was probably aimed at $A$. platys and not $A$. phagocytophilum. Similarly, E. canis can also have some degree of cross-reactivity with Anaplasma spp. [78, 79]. In the present study, 22 dogs seroreacted to both, $E$. canis and $A$. phagocytophilum, without positive PCR and sequencing. It could be suggested that these dogs were exposed only to one of the two vector-borne pathogens detected and they could have been infected by A. platys, the only Anaplasmataceae species detected by PCR. In addition, other species of Bartonella apart from $B$. henseale such as Bartonella vinsonii berkhoffii are associated with clinical illness in dogs. Therefore, the present study might have detected Bartonella seroreactivity related to infection with these other Bartonella species [80].

Another finding of the present study was the detection of a higher number of pathogens by IFAT and PCR in older dogs compared to young dogs. It is reasonable that older dogs would have more time and opportunity to be exposed to the different pathogens studied, although young dogs could be more susceptible to infections due to the immaturity of the immune system [81-84]. In agreement, Amusategui et al. [9] found that $R$. conorii infection was significantly associated with older age. However, a recent study [85] found that young animals are more susceptible to co-infection of Leishmania and Babesia spp. and Miró et al. [12] found that dogs under one year of age showed higher seropositivity rates for $E$. canis and Borrelia burgdorferi compared to dogs older than one year. Further studies are needed to understand the relationships between age and different vector-borne diseases, taking into account other factors such as lifestyle and location.

When studying vector-borne pathogens, it is also expected to find a relationship between the time of infection detection and the season when the vector is more active. In this study, only the results of IFAT for $A$. phagocytophilum antigen showed an association between seropositivity and season, in this case spring or winter. The vector for $A$. phagocytophilum present in Spain is the $I$. ricinus tick [15-17], which has the highest activity between April and June, a decrease of activity thereafter and a slight increase in the autumn-winter months [86]. When evaluating our results, it could be suggested that dogs with a positive IFAT for $A$. phagocytophilum were infested with these ticks and a subsequent infection occurred. However, I. ricinus is usually not found in the Mediterranean area [15, 76, 77, 86] and it parasites dogs only in rare cases since its natural hosts are wild animals such as rodents, wild boars and wild ruminants [15, 77]. Consequently, antibodies reactive with $A$. phagocytophilum are likely to have been formed against $A$. platys, for which the tick $R$. sanguineus (s.l) is suspected as its main vector. Different studies [76, 87, 88] have evaluated the seasonal dynamics of this tick in the Mediterranean basin and, although it has been stated that the highest activity of $R$. sanguineus (s.l.) is in summer, this tick can infest dogs during all seasons [76, 87]. Furthermore, $A$. platys is known to cause subclinical infections $[16,55,89]$ and in fact the detection of this infection might not be associated with a certain season. On the other hand, no association was found between other vector-borne pathogens and seasonality. This could be due to the high probability of subclinical or chronic infection with E. canis [16] with the consequent delay in detection of infection as well as with leishmaniosis $[2,4,6]$. 


\section{Conclusions}

This study demonstrates that dogs with clinical leishmaniosis from the Barcelona and Tarragona areas have a higher rate of co-infections with other vector-borne pathogens when compared with healthy controls. Furthermore, individual seroreactivity to $R$. conorii, E. canis, $A$. phagocytophilum and $B$. henselae antigens was associated with more pronounced clinicopathological abnormalities when compared with sick dogs that were seronegative to the same individual antigen. Interestingly, only seroreactivity of leishmaniotic dogs to $A$. phagocytophilum was associated with increased disease severity of clinical leishmaniosis.

\begin{abstract}
Abbreviations
ALT: Alanine aminotransferase; APTT: Activated partial thromboplastin time BAPGM: Bartonella/alpha-Proteobacteria growth medium; CanL: Canine leishmaniosis; CBC: Complete blood cell count; Cl: Confidence interval; ConA: Concavalin A; Ct: Cycle threshold; EDTA: Ethylenediaminetetraacetic acid; ELISA: Enzyme-linked immunosorbent assay; EU: ELISA unit; $\mathrm{H} 2 \mathrm{O}$ : water; H2SO4: sulfuric acid; HRM: High resolution melting;

IFAT: Immunofluorescence antibody test; IgG: Immunoglobulin G; LSA: L. infantum soluble antigen; MCH: Mean corpuscular hemoglobin; NTC: Nontemplate control; OD: Optical density; OR: Odds ratio; PBS: Phosphatebuffered saline; PCR: Polymerase chain reaction; $\mathrm{PPCR}$ : real-time PCR; RBC: Red blood cells; SD: Standard deviation; SFG: Spotted fever group; SPF: Specific pathogen free; UPC: Urinary protein/creatinine ratio; UV: Ultraviolet
\end{abstract}

\section{Acknowledgements}

The authors thank all veterinarians and dog owners that contributed to this study. Specially, we are grateful to Dr Marta Planellas (Hospital Clínic Veterinari of Universitat Autònoma de Barcelona, UAB), Marta Blanchart (Ars Veterinària), Montsant Osso (Consultori Falset) and Annabel Dalmau (Hospital Mediterrani). The authors are also grateful to Dr Lorena Alborch, Daniel Marí, Paulina Quirola and Maria Elisa Colvin (UAB) for the assistance with laboratory work. Publication of this paper has been sponsored by Bayer Animal Health in the framework of the 13th CVBD World Forum Symposium.

\section{Funding}

This study was supported by Spanish ministry grants, Ministerio de Economia y competitividad (MINECO) and FEDER, UE (AGL2012-32498 and AGL2015-68477) and Bayer Animal Health (Germany).

\section{Availability of data and materials}

The datasets supporting the conclusions of this article are included within the article and its additional files. All analysed data are available from the corresponding author upon reasonable request.

\section{Authors' contributions}

LS designed the research study. LS and GB supervised technical work. LS and $\mathrm{MB}$ contributed with data analysis, interpretation and wrote the manuscript. GB revised the manuscript. LO, LS and PM coordinated the veterinary clinics enrolled. PM, SM and LO performed whole blood assay and collection of supernatants. PM performed Leishmania ELISA and cytokine testing. AA and MB performed all IFATs. SM performed blood DNA extraction of samples and Leishmania real time PCR. AR performed filaroid real-time PCR and YNB performed Ehrlichia/Anaplasma and Babesia/Hepatozoon PCRs. All authors read and approved the final manuscript.

\section{Ethics approval}

All dogs enrolled in the study were privately owned pets for which client signed informed consent was obtained. Residual samples from blood EDTA tube and serum were used in this study; therefore, ethical approval was not required.

\section{Consent for publication}

Not applicable.

\section{Competing interests}

The authors declare that they have no competing interests.

\section{Publisher's Note}

Springer Nature remains neutral with regard to jurisdictional claims in published maps and institutional affiliations.

\section{Author details}

${ }^{1}$ Departament de Medicina i Cirurgia Animals, Facultat de Veterinària, Universitat Autònoma de Barcelona, Bellaterra, Spain. ${ }^{2}$ Hospital Clínic Veterinari, Facultat de Veterinària, Universitat Autònoma de Barcelona, Bellaterra, Spain. ${ }^{3}$ Koret School of Veterinary Medicine, Hebrew University, Rehovot, Israel.

Received: 16 November 2017 Accepted: 16 February 2018

Published online: 20 March 2018

\section{References}

1. Petrella V, Aceto S, Musacchia F, Colonna V, Robinson M, Benes V, et al. De novo assembly and sex-specific transcriptome profiling in the sand fly Phlebotomus perniciosus (Diptera, Phlebotominae), a major old world vector of Leishmania infantum. BMC Genomics. 2015:16:847.

2. Baneth G, Koutinas AF, Solano-Gallego L, Bourdeau P, Ferrer L. Canine leishmaniosis - new concepts and insights on an expanding zoonosis: part one. Trends Parasitol. 2008;24:324-30.

3. Solano-Gallego L, Morell P, Arboix M, Alberola J, Ferrer L. Prevalence of Leishmania infantum infection in dogs living in an area of canine leishmaniasis endemicity using PCR on several tissues and serology. J Clin Microbiol. 2001;39:560-3.

4. Solano-Gallego L, Koutinas A, Miró G, Cardoso L, Pennisi MG, Ferrer L, et al. Directions for the diagnosis, clinical staging, treatment and prevention of canine leishmaniosis. Vet Parasitol. 2009;165:1-18.

5. Zanette MF, Lima VM, Laurenti MD, Rossi CN, Vides JP, Vieira RF, et al. Serological cross-reactivity of Trypanosoma cruzi, Ehrlichia canis, Toxoplasma gondii, Neospora caninum and Babesia canis to Leishmania infantum chagasi tests in dogs. Rev Soc Bras Med Trop. 2014;47:105-7.

6. Pennisi MG. Leishmaniosis of companion animals in Europe: an update. Vet Parasitol. 2015;208:35-47.

7. Roura X, Breitschwerdt E, Lloret A, Ferrer L, Hegarty B. Serological evidence of exposure to Rickettsia, Bartonella and Ehrlichia species in healthy or Leishmania infantum-infected dogs from Barcelona, Spain. J Appl Res Vet Med. 2005:3:129-37.

8. Solano-Gallego L, Llull J, Osso M, Hegarty B, Breitschwerdt E. A serological study of exposure to arthropod-borne pathogens in dogs from northeastern Spain. Vet Res. 2006;37:231-44.

9. Amusategui I, Tesouro MA, Kakoma I, Sainz A. Serological reactivity to Ehrlichia canis, Anaplasma phagocytophilum, Neorickettsia risticii, Borrelia burgdorferi and Rickettsia conorii in dogs from northwestern Spain. Vector Borne Zoonotic Dis. 2008:8:797-803.

10. Tabar MD, Francino O, Altet L, Sánchez A, Ferrer L, Roura X. PCR survey of vector-borne pathogens in dogs living in and around Barcelona, an area endemic for leishmaniosis. Vet Rec. 2009;164:112-6.

11. Couto CG, Lorentzen L, Beall MJ, Shields J, Bertolone N, Couto Jl, et al. Serological study of selected vector-borne diseases in shelter dogs in central Spain using point-of-care assays. Vector Borne Zoonotic Dis. 2010;10: 885-8.

12. Miró G, Montoya A, Roura X, Gálvez R, Sainz A. Seropositivity rates for agents of canine vector-borne diseases in Spain: a multicentre study. Parasit Vectors. 2013;6:117.

13. Ortuño A, Pons I, Nogueras MM, Castellà J, Segura F. The dog as an epidemiological marker of Rickettsia conorii infection. Clin Microbiol Infect. 2009;15:241-2.

14. Espejo E, Andrés M, Pérez J, Prat J, Guerrero C, Muñoz MT, et al. Prevalence of antibodies to Rickettsia conorii in human beings and dogs from Catalonia: a 20-year perspective. Epidemiol Infect. 2016;144:1889-94.

15. Beugnet F, Marié JL. Emerging arthropod-borne diseases of companion animals in Europe. Vet Parasitol. 2009;163:298-305. 
16. Little SE. Ehrlichiosis and anaplasmosis in dogs and cats. Vet Clin North Am Small Anim Pract. 2010;40:1121-40.

17. Chomel B. Tick-borne infections in dogs - an emerging infectious threat. Vet Parasitol. 2011:179:294-301.

18. Dantas-Torres F, Chomel BB, Otranto D. Ticks and tick-borne diseases: a one health perspective. Trends Parasitol. 2012;28:437-46.

19. Solano-Gallego L, Caprì A, Pennisi MG, Caldin M, Furlanello T, Trotta M. Acute febrile illness is associated with Rickettsia spp infection in dogs. Parasit Vectors. 2015;8:216.

20. Doudier B, Olano J, Parola P, Brouqui P. Factors contributing to emergence of Ehrlichia and Anaplasma spp. as human pathogens. Vet Parasitol. 2010; 167:149-54.

21. Regier Y, O'Rourke F, Kempf VA. Bartonella spp. - a chance to establish one health concepts in veterinary and human medicine. Parasit Vectors. 2016;9: 261.

22. Montoya-Alonso JA, Morchón R, Falcón-Cordón Y, Falcón-Cordón S, Simón F, Carretón E. Prevalence of heartworm in dogs and cats of Madrid, Spain. Parasit Vectors. 2017;10:354.

23. Montoya-Alonso JA, Carretón E, Simón L, González-Miguel J, García-Guasch $L$, Morchón R, et al. Prevalence of Dirofilaria immitis in dogs from Barcelona: validation of a geospatial prediction model. Vet Parasitol. 2015;212:456-9.

24. Simón F, Siles-Lucas M, Morchón R, González-Miguel J, Mellado I, Carretón E, et al. Human and animal dirofilariasis: the emergence of a zoonotic mosaic. Clin Microbiol Rev. 2012;25:507-44.

25. Tuttle AD, Birkenheuer AJ, Juopperi T, Levy MG, Breitschwerdt EB. Concurrent bartonellosis and babesiosis in a dog with persistent thrombocytopenia. J Am Vet Med Assoc. 2003;223:1306-10.

26. De Tommasi AS, Otranto D, Dantas-Torres F, Capelli G, Breitschwerdt EB, de Caprariis D. Are vector-borne pathogen co-infections complicating the clinical presentation in dogs? Parasit Vectors. 2013;6:97.

27. Baneth G, Harrus S, Gal A, Aroch I. Canine vector-borne co-infections: Ehrlichia canis and Hepatozoon canis in the same host monocytes. Vet Parasitol. 2015;208:30-4.

28. Cringoli G, Rinaldi L, Capuano F, Baldi L, Veneziano V, Capelli G. Serological survey of Neospora caninum and Leishmania infantum co-infection in dogs. Vet Parasitol. 2002;106:307-13.

29. Cardinot CB, Silva JE, Yamatogi RS, Nunes CM, Biondo AW, Vieira RF, et al. Detection of Ehrlichia canis, Babesia vogeli and Toxoplasma gondii DNA in the brain of dogs naturally infected with Leishmania infantum. J Parasitol. 2016;102:275-9.

30. Mekuzas Y, Gradoni L, Oliva G, Foglia Manzillo V, Baneth G. Ehrlichia canis and Leishmania infantum co-infection: a 3-year longitudinal study in naturally exposed dogs. Clin Microbiol Infect. 2009;15:30-1.

31. Mylonakis ME, Soubasis N, Balakrishnan N, Theodorou K, Kasabalis D, Saridomichelakis M, et al. Molecular identification of Bartonella species in dogs with leishmaniosis (Leishmania infantum) with or without cytological evidence of arthritis. Vet Microbiol. 2014;174:272-5.

32. Meléndez-Lazo A, Ordeix L, Planellas M, Pastor J, Solano-Gallego L. Clinicopathological findings in sick dogs naturally infected with Leishmania infantum: comparison of five different clinical classification systems. Res Vet Sci. 2017;117:18-27.

33. Solano-Gallego L, Di Filippo L, Ordeix L, Planellas M, Roura X, Altet L, et al. Early reduction of Leishmania infantum-specific antibodies and blood parasitemia during treatment in dogs with moderate or severe disease. Parasit Vectors. 2016:9:235

34. Solano-Gallego L, Montserrat-Sangrà S, Ordeix L, Martínez-Orellana P. Leishmania infantum-specific production of IFN- $\gamma$ and IL-10 in stimulated blood from dogs with clinical leishmaniosis. Parasit Vectors. 2016;9:317.

35. Montserrat-Sangrà S, Alborch L, Ordeix L, Solano-Gallego L. TLR-2 and TLR-4 transcriptions in unstimulated blood from dogs with leishmaniosis due to Leishmania infantum at the time of diagnosis and during follow-up treatment. Vet Parasitol. 2016;228:172-9.

36. Peleg O, Baneth G, Eyal O, Inbar J, Harrus S. Multiplex real-time qPCR for the detection of Ehrlichia canis and Babesia canis vogeli. Vet Parasitol. 2010;173: 292-9.

37. Parola P, Roux V, Camicas JL, Baradji I, Brouqui P, Raoult D. Detection of ehrlichiae in African ticks by polymerase chain reaction. Trans $\mathrm{R}$ Soc Trop Med Hyg. 2000;94:707-8.

38. Tabar MD, Altet L, Francino O, Sánchez A, Ferrer L, Roura X. Vector-borne infections in cats: molecular study in Barcelona area (Spain). Vet Parasitol. 2008;151:332-6.
39. Olmeda AS, Armstrong PM, Rosenthal BM, Valladares B, del Castillo A, de Armas F, et al. Short report: a subtropical case of human babesiosis. Acta Trop. 1997;67:229-34.

40. Rojas A, Rojas D, Montenegro VM, Baneth G. Detection of Dirofilaria immitis and other arthropod-borne filarioids by an HRM real-time GPCR, bloodconcentrating techniques and a serological assay in dogs from Costa Rica. Parasit Vectors. 2015;8:170.

41. Wongkamchai S, Monkong N, Mahannol P, Taweethavonsawat P, Loymak S, Foongladda S. Rapid detection and identification of Brugia malayi, $B$. pahangi, and Dirofilaria immitis by high-resolution melting assay. Vector Borne Zoonotic Dis. 2013;13:31-6.

42. Rose J, Nachum-Biala Y, Mumcuoglu KY, Alkhamis MA, Ben-Nun A, Lensky I, et al. Genetic characterization of spotted fever group rickettsiae in questing ixodid ticks collected in Israel and environmental risk factors for their infection. Parasitology. 2017;144:1088-101.

43. Tabar MD, Altet L, Martínez V, Roura X. Wolbachia, filariae and Leishmania coinfection in dogs from a Mediterranean area. J Small Anim Pract. 2013;54: $174-8$.

44. Toepp A, Larson M, Grinnage-Pulley T, Lima A, Bennett C, Wilson G, et al. Co-infection with tick-borne diseases causes clinical progression of leishmaniosis in dogs. 6th World Congress on Leishmaniasis, 16-20 May, Toledo, Spain; 2017. p. 979

45. Estevez JO, Nevor MC, Russo PD, Chandrashekar R, Tyrrell P, Saucier J, et al. Association of tick-borne co-infections with severity of canine visceral leishmaniosis in dogs from northeastern Argentina. 6th World Congress on Leishmaniasis, 16-20 May, Toledo, Spain; 2017. p. 955.

46. Lima AL, Toepp A, Larson M, Grinnage-Pulley T, Bennett C, Wilson G, et al. Is canine ehrlichiosis causing progression of clinical leishmaniosis in dogs? Toledo: 6th World Congress on Leishmaniasis; 2017. p. 959.

47. Rodriguez Sánchez A, Rodriguez Valinotti MF, Chandrashekar R, Leutenegger CM, Estrada M, Tyrrell P, et al. Survey of vector-borne comorbidities in Leishmania-endemic canine population from Paraguay. Toledo: 6th World Congress on Leishmaniasis; 2017. p. 1309.

48. Solano-Gallego L, Bradley J, Hegarty B, Sigmon B, Breitschwerdt E. Bartonella henselae lgG antibodies are prevalent in dogs from southeastern USA. Vet Res. 2004:35:585-95.

49. Cortese L, Pelagalli A, Piantedosi D, Mastellone V, Manco A, Lombardi P, et al. Platelet aggregation and haemostatic response in dogs naturally co-infected by Leishmania infantum and Ehrlichia canis. J Vet Med A Physiol Pathol Clin Med. 2006;53:546-8.

50. Cortese L, Pelagalli A, Piantedosi D, Cestaro A, Di Loria A, Lombardi P, et al. Effects of therapy on haemostasis in dogs infected with Leishmania infantum, Ehrlichia canis, or both combined. Vet Rec. 2009;164:433-4.

51. Cortese L, Terrazzano G, Piantedosi D, Sica M, Prisco M, Ruggiero G, et al. Prevalence of anti-platelet antibodies in dogs naturally co-infected by Leishmania infantum and Ehrlichia canis. Vet J. 2011;188:118-21.

52. Kohn B, Galke D, Beelitz P, Pfister K. Clinical features of canine granulocytic anaplasmosis in 18 naturally infected dogs. J Vet Intern Med. 2008:22:1289-95.

53. Al Izzi S, Martin DS, Chan RY, Leutenegger CM. Babesia canis vogeli, Ehrlichia canis, and Anaplasma platys infection in a dog. Vet Clin Pathol. 2013:42:471-5.

54. Dondi F, Russo S, Agnoli C, Mengoli N, Balboni A, Alberti A, et al. Clinicopathological and molecular findings in a case of canine Anaplasma phagocytophilum infection in northern Italy. Sci World J. 2014;2014

55. Bouzouraa T, René-Martellet M, Chêne J, Attipa C, Lebert I, Chalvet-Monfray $K$, et al. Clinical and laboratory features of canine Anaplasma platys infection in 32 naturally infected dogs in the Mediterranean basin. Ticks Tick Borne Dis. 2016;7:1256-64

56. Escribano D, Cihan H, Martínez-Subiela S, Levent P, Kocaturk M, Aytug N, et al. Changes in serum proteins in dogs with Ehrlichia canis infection. Microb Pathog. 2017;113:34-9.

57. Torrente C, Manzanilla EG, Bosch L, Fresno L, Rivera Del Alamo M, Andaluz A, et al. Plasma iron, C-reactive protein, albumin, and plasma fibrinogen concentrations in dogs with systemic inflammatory response syndrome. J Vet Emerg Crit Care. 2015;25:611-9.

58. Procajło A, Skupień EM, Bladowski M, Lew S. Monocytic ehrlichiosis in dogs. Pol J Vet Sci. 2011;14:515-20

59. Pantchev N, Pluta S, Huisinga E, Nather S, Scheufelen M, Vrhovec MG, et al. Tick-borne diseases (Borreliosis, Anaplasmosis, Babesiosis) in German and Austrian dogs: status quo and review of distribution, transmission, clinical findings, diagnostics and prophylaxis. Parasitol Res. 2015;114:19-54. 
60. Hornok S, Sándor AD, Tomanović S, Beck R, D’Amico G, Kontschán J, et al. East and west separation of Rhipicephalus sanguineus mitochondrial lineages in the Mediterranean basin. Parasit Vectors. 2017;10:39.

61. Mrljak V, Kuleš J, Mihaljević Ž, Torti M, Gotić J, Crnogaj M, et al. Prevalence and geographic distribution of vector-borne pathogens in apparently healthy dogs in Croatia. Vector-Borne Zoonotic Dis. 2017;17:398-408.

62. Latrofa MS, Angelou A, Giannelli A, Annoscia G, Ravagnan S, Dantas-Torres F, et al. Ticks and associated pathogens in dogs from Greece. Parasit Vectors. 2017;10:301

63. Diakou A, Kapantaidakis E, Tamvakis A, Giannakis V, Strus N. Dirofilaria infections in dogs in different areas of Greece. Parasit Vectors. 2016;9: 508.

64. Tahir D, Bittar F, Barré-Cardi H, Sow D, Dahmani M, Mediannikov O, et al. Molecular survey of Dirofilaria immitis and Dirofilaria repens by new real-time TaqMan ${ }^{\circledast}$ PCR assay in dogs and mosquitoes (Diptera: Culicidae) in Corsica (France). Vet Parasitol. 2017;235:1-7

65. Attipa C, Hicks CA, Barker EN, Christodoulou V, Neofytou K, Mylonakis ME, et al. Canine tick-borne pathogens in Cyprus and a unique canine case of multiple co-infections. Ticks Tick Borne Dis. 2017;8:341-6.

66. Rjeibi MR, Rouatbi M, Mabrouk M, Tabib I, Rekik M, Gharbi M. Molecular study of Dirofilaria immitis and Dirofilaria repens in dogs from Tunisia. Transbound Emerg Dis. 2017;64:1505-9.

67. Azmi K, Al-Jawabreh A, Nasereddin A, Abdelkader A, Zaid T, Ereqat S, et al. Detection and molecular identification of Hepatozoon canis and Babesia vogeli from domestic dogs in Palestine. Parasitology. 2017;144:613-21.

68. Nicholson WL, Allen KE, McQuiston JH, Breitschwerdt EB, Little SE. The increasing recognition of rickettsial pathogens in dogs and people. Trends Parasitol. 2010;26:205-12.

69. Otranto D, Testini G, Dantas-Torres F, Latrofa MS, Diniz PP, de Caprariis D, et al. Diagnosis of canine vector-borne diseases in young dogs: a longitudinal study. J Clin Microbiol. 2010;48:3316-24.

70. Kidd L, Qurollo B, Lappin M, Richter K, Hart JR, Hill S, et al. Prevalence of vector-borne pathogens in southern California dogs with clinical and laboratory abnormalities consistent with immune-mediated disease. J Vet Intern Med. 2017;31:1081-90.

71. Solano-Gallego L, Trotta M, Caldin M, Furlanello T. Molecular survey of Rickettsia spp. in sick dogs in Italy. Zoonoses Public Health. 2008;55:521-5.

72. Duncan AW, Maggi RG, Breitschwerdt EB. A combined approach for the enhanced detection and isolation of Bartonella species in dog blood samples: pre-enrichment liquid culture followed by PCR and subculture onto agar plates. J Microbiol Methods. 2007;69:273-81.

73. Merino FJ, Nebreda T, Serrano JL, Fernández-Soto P, Encinas A, PérezSánchez R. Tick species and tick-borne infections identified in population from a rural area of Spain. Epidemiol Infect. 2005;133:943-9.

74. Fernández-Soto P, Pérez-Sánchez R, Álamo-Sanz R, Encinas-Grandes A. Spotted fever group rickettsiae in ticks feeding on humans in northwestern Spain: is Rickettsia conorii vanishing? Ann N Y Acad Sci. 2006;1078:331-3.

75. Aguirre E, Tesouro MA, Ruiz L, Amusategui I, Sainz A. Genetic characterization of Anaplasma (Ehrlichia) platys in dogs in Spain. J Vet Med B Infect Dis Vet Public Heal. 2006;53:197-200.

76. Estrada-Peña A, Roura X, Sainz A, Miró G, Solano-Gallego L. Species of ticks and carried pathogens in owned dogs in Spain: results of a one-year national survey. Ticks Tick Borne Dis. 2017:8:443-52.

77. Estrada-Peña A, Martinez JM, Sanchez Acedo C, Quilez J, Del Cacho E. Phenology of the tick, Ixodes ricinus, in its southern distribution range (central Spain). Med Vet Entomol. 2004;18:387-97.

78. Waner T, Harrus S, Jongejan F, Bark H, Keysary A, Cornelissen AW Significance of serological testing for ehrlichial diseases in dogs with special emphasis on the diagnosis of canine monocytic ehrlichiosis caused by Ehrlichia canis. Vet Parasitol. 2001;95:1-15.

79. Gaunt S, Beall M, Stillman B, Lorentzen L, Diniz P, Chandrashekar R, et al. Experimental infection and co-infection of dogs with Anaplasma platys and Ehrlichia canis: hematologic, serologic and molecular findings. Parasit Vectors. 2010;3:33.

80. Breitschwerdt EB. Bartonellosis, one health and all creatures great and small. Vet Dermatol. 2017;28:96-e21.

81. Greeley EH, Ballam JM, Harrison JM, Kealy RD, Lawler DF, Segre M. The influence of age and gender on the immune system: a longitudinal study in Labrador retriever dogs. Vet Immunol Immunopathol. 2001;82:57-71.
82. Blount DG, Pritchard DI, Heaton PR. Age-related alterations to immune parameters in Labrador retriever dogs. Vet Immunol Immunopathol. 2005; 108:399-407.

83. Day MJ. Immune system development in the dog and cat. J Comp Pathol. 2007;137:10-5.

84. Day MJ. Ageing, immunosenescence and inflammageing in the dog and cat. J Comp Pathol. 2010;142:S60-9.

85. Santana Almeida A, Almeida-Souza F, Lima Rocha A, Carvalho-Neta Vieira A, Carvalho Cardoso R, Henrique Evangelista FA, et al. Coinfection of Leishmania infantum and Babesia canis vogeli in dogs from urban and rural area from northeast Brazil. Toledo: 6th World Congress on Leishmaniasis; 2017. p. 1490.

86. Barandika JF, Olmeda SA, Casado-Nistal MA, Hurtado A, Juste RA, Valcárcel F, et al. Differences in questing tick species distribution between atlantic and continental climate regions in Spain. J Med Entomol. 2011:48:13-9.

87. Lorusso V, Dantas-Torres F, Lia RP, Tarallo VD, Mencke N, Capelli G, et al. Seasonal dynamics of the brown dog tick, Rhipicephalus sanguineus, on a confined dog population in Italy. Med Vet Entomol. 2010;24:309-15.

88. Dantas-Torres F, Figueredo LA, Otranto D. Seasonal variation in the effect of climate on the biology of Rhipicephalus sanguineus in southern Europe. Parasitology. 2011;138:527-36.

89. Bradfield JF, Vore SJ. Pryor WH Jr. Ehrlichia platys infection in dogs. Lab Anim Sci. 1996;46:565-8

\section{Submit your next manuscript to BioMed Central and we will help you at every step:}

- We accept pre-submission inquiries

- Our selector tool helps you to find the most relevant journal

- We provide round the clock customer support

- Convenient online submission

- Thorough peer review

- Inclusion in PubMed and all major indexing services

- Maximum visibility for your research

Submit your manuscript at www.biomedcentral.com/submit
C) Biomed Central 